\section{Alcohols and Carnation Senescence}

\author{
Meng-Jen Wu, Lorenzo Zacarias', Mikal E. Saltveit ${ }^{2}$, and \\ Michael S. Reid \\ Department of Environmental Horticulture, University of California, \\ Davis, CA 95616
}

Additional index words. Dianthus calyophyllus, vase life, ethylene, ACC, EFE, ethylene sensitivity

\begin{abstract}
Continuous treatment with $8 \%$ ethanol doubled the vase life of 'White Sim' carnation (Dianthus caryophyllus L.) flowers. Other alcohols, other concentrations of ethanol, or pulse treatments with up to $8 \%$ ethanol had little or no effect. Butanol and longer-chain alcohols shortened vase life and caused the flower stem to fold. During their eventual senescence, the petals of ethanol-treated flowers did not inroll; instead, individual petals dried slowly from their tips. Very little ethylene was produced by ethanol-treated flowers, and the normal increase in ACC content and EFE activity was also suppressed. Ethanol treatment also decreased the flowers' sensitivity to exogenous ethylene.
\end{abstract}

The senescence of cut carnation flowers is normally accompanied by a marked increase in the synthesis of ethylene and a concomitant climacteric rise in respiration. Treatment of flowers with either inhibitors of ethylene biosynthesis such as aminoethoxyvinylglytine (AVG) (Baker et al., 1977) and aminooxyacetic acid (AOA) (Fujino et al., 1981) or inhibitors of ethylene action such as silver thiosulfate (STS) (Veen, 1979) delays the onset of flower senescence. Pretreatment with STS has become standard procedure in the commercial marketing of carnations (Reid et al., 1980). The potential environmental concerns about the use of this heavy metal-containing compound suggests the need for developing a substitute means of controlling flower senescence. Although 2,5-norbornadiene (NBD) has proved useful as an experimental tool for manipulating ethylene responses in carnations and other ethylenesensitive tissues (Sisler et al., 1986), NBD is volatile, foul smelling, and toxic, and therefore not suited to commercial use. Its effectiveness does, however, show that the possibilities of interfering with ethylene effects in cut flowers extend beyond the use of $\mathrm{Ag}^{+}$. Exogenous application of ethanol has been shown to delay the senescence of tomatoes (Solanum tuberosum Mill.)(Kelly and Saltveit, 1988), oat (Avena sativa L.) leaves (Satler and Thimann, 1980), and carnation flowers (Heins, 1980). In tomatoes, short-term exposure to ethanol delayed or suppressed the ethylene climacteric (Kelly and Saltveit, 1988) and it also appeared to interfere with the action of ethylene (Saltveit and Mencarelli, 1988; Saltveit, 1989). Heins (1980) suggested that ethanol inhibited the

Received for publication 17 Dec. 1990. Accepted for publication 10 Sept. 1990. The cost of publishing this paper was defrayed in part by the payment of page charges. Under postal regulations, this paper therefore must be hereby marked advertisement solely to indicate this fact.

'Permanent address: Instituto Valenciano de Investigaciones Agrarias, Apto. Oficial. 46113 Moncada, Valencia, Spain.

${ }^{2}$ Dept. of Vegetable Crops. conversion of ACC to ethylene in nonclimacteric tissue but not in the climacteric tissues of carnation flowers. The mechanism by which ethanol retards senescence in cut carnations, however, has not been completely elucidated.

Satler and Thimann (1980) reported that the senescence-retarding effects of straightchain alcohols in the detached oat leaf assay increased in a log-linear fashion with increased chain length from ethanol to n-octanol. Although Heins (1980) tested the effect of $2 \%$ methanol, ethanol, propanol, and butanol on carnation flowers, the applicability of the findings on oat leaves to carnations has not yet been completely tested.

The potential usefulness of alcohols in extending the life of carnations indicates the need for an investigation of the effect of longer-chain alcohols and of the mechanism by which it exerts its effect. In this study, we examined the effects of continuous and pulse treatment of carnations with various alcohols on their vase life. The mechanism by which ethanol delays ethylene synthesis and action in flower senescence was also explored.

Procedures. 'White Sim' carnations were grown in the greenhouse at $21 / 15 \mathrm{C}$ day/night cycles using standard production methods,

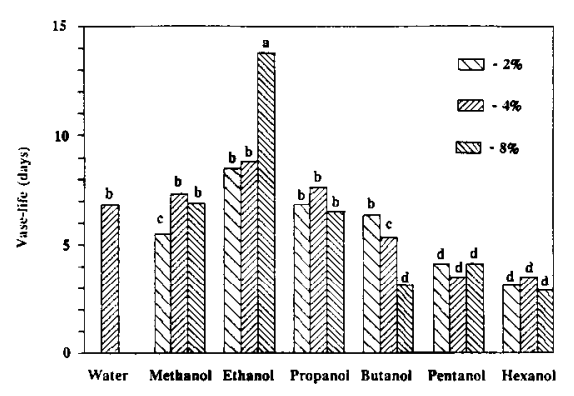

Fig. 1. Vase life of 'White Sim' carnation flowers in water and in various concentrations of six straight-chain alcohols $\left(\mathrm{C}_{1}-\mathrm{C}_{6}\right)$. Flowers were harvested at commercial maturity, then placed in the alcohol solutions for determination of vase life. Mean separation by Duncan's multiple range test, $P \leq 0.05$. or obtained from a commercial grower and transported dry under cool conditions to Univ. of California, Davis, on the day of harvest. Experiments were started on the day of harvest. Flowers were normally harvested at commercial maturity (outer petals horizontal). The flowers were trimmed to a length of $40 \mathrm{~cm}$, then placed individually in test solutions or in deionized water (DI) containing $200 \mathrm{ppm}$ of the biocide Physan-20 (Consan Pacific, Whittier, Calif.). The life of the flowers was evaluated under standard conditions [20C, $12 \mathrm{~h}$ cool-white fluorescent light, $55 \%$ relative humidity (Reid and Kofranek, 1981)]. The flowers were examined twice a day; vase life was considered terminated when the corolla was noticeably wilted, dried, or necrotic. In experiments determining postharvest changes in fresh weight, flowers were removed from the vases daily and weighed.

Ethanol solutions were prepared fresh each time from $95 \%$ ethanol. Solutions of other alcohols were prepared fresh from reagent grade alcohols. Exogenous ethylene was applied by placing flowers in large glass tanks ventilated with flowing streams of air $(\approx 30$ liter $\cdot \mathrm{h}^{-1}$ ) containing ethylene at the desired concentrations. Ethylene concentrations in the tanks were monitored daily. When we tested the effect of ethanol on ethylene responses, we placed the flowers in the ethanol solution $3 \mathrm{~h}$ before starting the ethylene treatments.

Respiration and ethylene production by the flowers were determined as described by $\mathrm{Wu}$ et al. (1989). The 1-aminocyclopropane-1carboxylic acid (ACC) content of the flowers was determined, using petals from the outermost whorl, by the technique of Bufler et al. (1980). Ethylene-forming enzyme (EFE) activity in petals was determined following the methods described by Whitehead et al. (1984).

To measure the respiration and ethylene production of ethylene-treated flowers, flowers were first removed from the treatment tanks, then sealed individually for a short time in 500-ml jars fitted with a rubber



Fig. 2. Effect of ethanol concentration in holding solutions on the fresh weight of 'White Sim' carnation flowers. Data are the means \pm SE of two experiments, each with five replications per treatment. Where no error bar appears, the SE was smaller than the size of the symbol. 




Fig. 3. Respiration (a) and ethylene production rates (b; note logarithmic scale) of 'White Sim' carnation flowers harvested at commercial maturity, with pedicels trimmed to $5 \mathrm{em}$, then placed in respiration jars with their pedicels immersed in various concentrations of ethanol. Data are the means $\pm \mathbf{S E}$ of two experiments, each with five replications per treatment. Where no error bar appears, the SE was smaller than the size of the symbol.

sampling port. The ethylene and $\mathrm{CO}_{2}$ content of headspace air samples taken from the jar were used to calculate the ethylene production and respiration rates of the flowers.

Effects of various alcohols. Ethanol was by far the most effective of the alcohols tested in improving carnation vase life (Fig. 1). Ethanol at $8 \%$ doubled the life of the flowers relative to the water control, while $2 \%$ and $4 \%$ ethanol increased vase life of tested flowers slightly (20\%). Methanol- and propanol-treated flowers had the same vase life as the control flowers. Ethanol has previously been reported to cause stem topple in carnation flowers (Heins, 1980). Butanol and longer-chain alcohols shortened vase life by causing the flower stems to topple (Table 1). The stem always collapsed at the node immediately above the vase solution, and subsequently at all the other nodes up the stem. This effect was more rapid and more frequent in the higher concentrations of longerchain alcohols (Table 1). Even at lower concentrations, which did not cause stem collapse, the longer-chain alcohols failed to prolong flower vase life (data not shown).

Table 1. Incidence of stem topple in 'White Sim' carnation flowers held in various alcohol solutions. Data are the means of two experiments (five replicates per treatment).

\begin{tabular}{|c|c|c|c|c|c|c|c|c|c|}
\hline \multirow[b]{4}{*}{ Alcohol $^{z}$} & \multicolumn{9}{|c|}{ Treatment durations (h) } \\
\hline & \multicolumn{3}{|c|}{12} & \multicolumn{3}{|c|}{48} & \multicolumn{3}{|c|}{96} \\
\hline & \multicolumn{9}{|c|}{ Alcohol conen (\%) } \\
\hline & 2 & 4 & 8 & 2 & 4 & 8 & 2 & 4 & 8 \\
\hline \multicolumn{10}{|c|}{ Toppled stems (\%) } \\
\hline Methanol & 0 & 0 & 0 & 0 & 0 & 0 & 0 & 0 & 0 \\
\hline Ethanol & 0 & 0 & 0 & 0 & 0 & 0 & 0 & 0 & 0 \\
\hline Propanol & 0 & 0 & 0 & 0 & 60 & 80 & 0 & 100 & 100 \\
\hline Butanol & 0 & 80 & 60 & 60 & 80 & 60 & 80 & 100 & 80 \\
\hline Pentanol & 20 & 60 & 80 & 80 & 80 & 100 & 100 & 80 & 100 \\
\hline Hexanol & 40 & 60 & 80 & 80 & 60 & 80 & 80 & 80 & 80 \\
\hline
\end{tabular}

${ }^{2}$ Water control, none toppled.
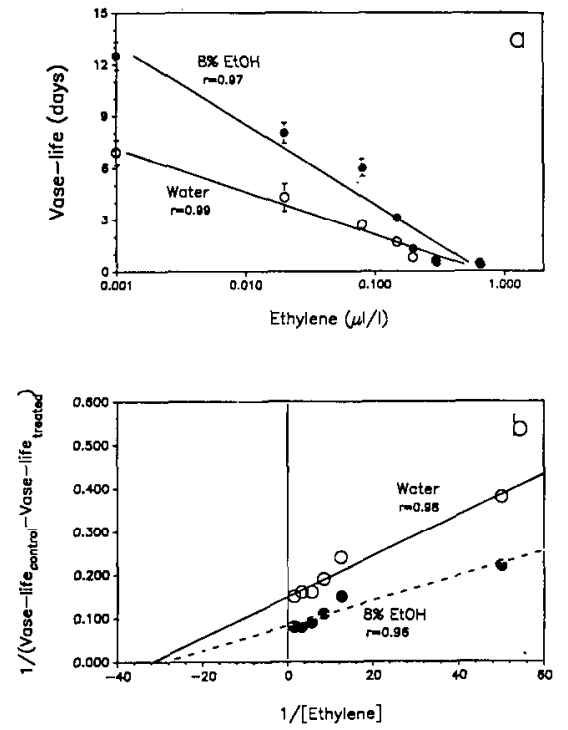

Fig. 4. Effect of ethanol on the response of 'White Sim' carnations to various concentrations of ethylene. Data are the means \pm SE of four exment. Where no error bar appears, the SE was smaller than the size of the symbol. The data are fitted to linear regressions (a); and a double reciprocal representation (b).

The senescence of ethanol-treated carnation flowers, as indicated by Heins (1980), did not show the typical petal inrolling; instead, individual petals dried slowly from their tips.

In senescing oat leaves treated with various alcohols, senescence was increasingly delayed as the chain length of the alcohol increased (Satler and Thimann, 1980). In contrast, alcohols other than ethanol had little effect on the life of carnation flowers, and higher-chain-length alcohols were deleterious, causing stem topple. These data agree with those in previous studies of carnation senescence (Heins and Blakely, 1980) and tomato ripening (Kelly and Saltveit, 1988), and suggest either that ethylene action in oat leaves is very different from that in carnations, or that the alcohols are acting in a different way to prevent senescence in these different systems. Satler and Thimann (1980) showed that the higher alcohols decreased diffusive resistance in oat leaves, indicating that they stimulated stomatal opening, which may have been the means by which they reduced the rate of senescence. periments, each with five replicates per treat-

Fig. 5. Effect of exogenous ethylene on the respiration rate of ethanol-treated carnations. Flowers harvested at commercial maturity were placed in water (a) or $8 \%$ ethanol (b) $3 \mathrm{~h}$ before the various concentrations of ethylene were applied. At intervals, flowers were removed for measurement of respiration. Data are the means $\pm \mathrm{se}$ of two experiments, each with five replications per treatment. Where no error bar appears, the SE was smaller than the size of the symbol.

Effects of ethanol concentrations and of pulse treatment. The vase life of carnations increased with increasing ethanol concentrations up to $8 \%$. Higher concentrations provided no additional benefit, and sometimes caused stem topple (data not shown). These data agree with those in previous studies of carnation senescence (Heins, 1980). The effects of ethanol concentration on flower fresh weight mirrored its effects on vase life. Alcohol treatment reduced fresh weight gain early in vase life, but delayed the rapid fall associated with normal senescence (Fig. 2).

Although Kelly and Saltveit (1988) found that short-term treatments with ethanol inhibited ripening of tomatoes, the beneficial effects of alcohol on carnations were present only in flowers treated continuously. Heins and Blakely (1980) had reported that a 24-h pulse treatment with $2 \%$ ethanol was ineffective in delaying carnation senescence. Pulse treatment with higher concentrations of ethanol (up to $8 \%$ ) for longer times (up to $48 \mathrm{~h}$ ) did not extend vase life of the flowers (data not shown).

Respiration and ethylene production. All three ethanol concentrations tested partially suppressed the typical respiratory peak without changing the time of its occurrence (Fig. $3 a)$. In contrast, ethylene production was very strongly suppressed at all ethanol concentrations (Fig. 3b). Even 2\% ethanol, which had little effect on vase life, reduced the peak of ethylene production to one-one hundreth that of the controls.

Effect of exogenous ethylene. Treatment of carnations with $8 \%$ ethanol reduced the senescence-promoting effects of exogenous ethylene at concentrations $<0.6 \mu \mathrm{l} \cdot$ liter $^{-1}$ (Fig. 4a). The ethylene-induced respiratory peak in the ethanol-treated flowers was likewise reduced and delayed with respect to the 


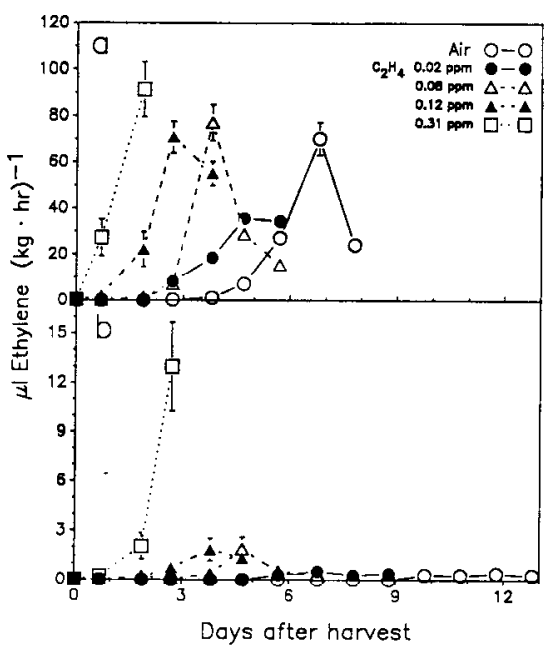

Fig. 6. Effect of exogenous ethylene on ethylene production by ethanol-treated carnations. Flowers harvested at commercial maturity were placed in water (a) or $8 \%$ ethanol (b) $3 \mathrm{~h}$ before the various concentrations of ethylene were applied. At intervals, flowers were removed for measurement of ethylene production. Data are the means \pm SE of two experiments, each with five replications per treatment. Where no error bar appears, the $\mathbf{S E}$ was smaller than the size of the symbol.

water controls (Fig. 5). This effect was also apparent in ethylene-induced ethylene production, which was strongly suppressed, and markedly retarded in flowers treated with ethanol (Fig. 6).

The effects of ethylene concentrations on the senescence of control and ethanol-treated flowers (Fig. 4a) can be expressed as a double-reciprocal plot (Fig. 4b), which suggests that the inhibition of ethylene action in carnation senescence by ethanol is noncompetitive. In tomatoes, too, inhibition of ripening by ethanol appears to inhibit ethylene action noncompetitively (Saltveit, 1989).

Ethylene biosynthetic pathway. Ethanol treatment of flowers not only suppressed ethylene evolution, but also reduced the accumulation of ACC and completely inhibited activity of the EFE (Fig. 7).

The present work confirms previous studies that indicate that ethanol is capable of retarding senescence in carnation flowers (Heins, 1980; Heins and Blakely, 1980). However, the marked effects of ethanol on the life of cut carnations appear, from our data, to be due to pronounced inhibition of ethylene action in addition to suppression of ethylene synthesis. Heins (1980) suggested that ethanol acted by inhibiting ethylene production, and although it is true that ethanol-

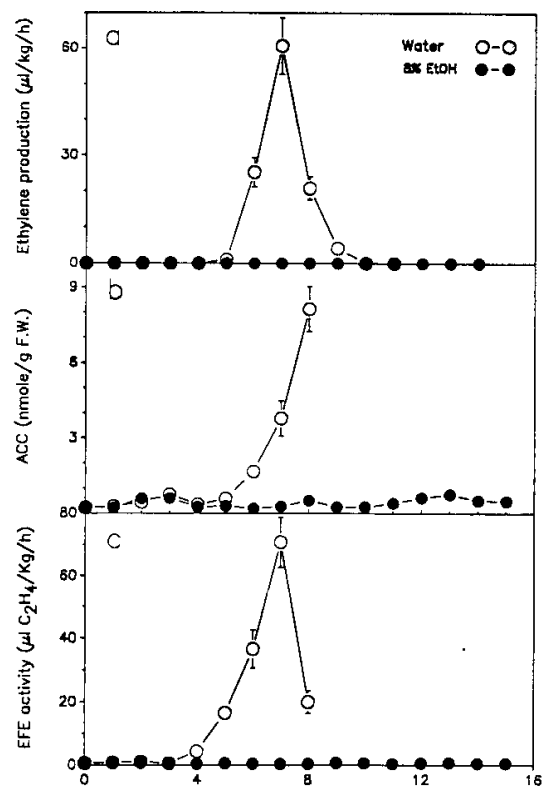

Days ofter horvest

Fig. 7. Ethylene production (a); ACC content (b); and EFE activity (c) of 'White Sim' carnation flowers held in water or in an $8 \%$ ethanol solution. Flowers were harvested at commercial maturity, divided into two groups, then placed in a large tank ventilated with ethylene-free air. At intervals four flowers from one group were removed for measurement of ethylene production, then placed back in the tank. At the same time, replicate flowers from the other tank were analyzed for ACC content or EFE activity. Data are the means \pm SE of two experiments, each with four replications per treatment. Where no error bar appears, the SE was smaller than the size of the symbol.

treated flowers produced almost no ethylene, even at the end of their vase life (Fig. 3b), two key components of the biosynthetic pathway appear to be inhibited (Fig. 7). This result suggests that the primary effect of ethanol may be at an earlier level, preventing the induction of increased ethylene biosynthesis.

Taken together, these data suggest that, in addition to inhibiting ethylene synthesis, ethanol interferes with ethylene action, but in some other way than by competing with ethylene for its binding site. Although ethanol is a useful additional tool to study the role of ethylene in flower senescence, its practical value is limited by the need to treat flowers constantly, perhaps a result of the much higher surface : volume ratio of herbacious parts of plants, which would result in more rapid volatilization of the inhibitor than from a bulky and relatively impermeable product like tomato fruits. Our results suggest that ethanol could be used by purchasers of carnation flowers to retard their senescence, and point to the need for exploration of related compounds that may interfere with ethylene action without constant application.

\section{Literature Cited}

Baker, J.E., C.Y. Wang, M. Liberman, and R.E. Hardenburg. 1977. Delay of senescence in carnations by a rhizobitoxine analogue and sodium benzoate. HortScience 12:38-39.

Bufler, G., Y. Mor, MS. Reid, and S.F. Yang. 1980. Changes in 1-aminocyclopropane-1-carboxylic acid-content of cut carnation flowers in relation to their senescence. Planta 150:439442.

Fujino, D.W., M.S. Reid, and S.F Yang. 1981. Effects of aminooxyacetic acid on postharvest characterstics of carnation. Acta Hort. 113:5964.

Heins, R.D. 1980. Inhibition of ethylene synthesis and senescence in carnation by ethanol. J. Amer. Soc. Hort. Sci. 105:141-144.

Heins, R.D. and N. Blakely. 1980. Influence of ethanol on ethylene biosynthesis and flower senescence of cut carnation. Scientia Hort. 13:361369.

Kelly, M.O. and M.E. Saltveit. 1988. Effect of endogenously synthesized and exogenously applied ethanol on tomato fruit ripening. Plant Physiol. 88:143-147.

Reid, M.S. and A.M. Kofranek. 1981. Recommendations for standardized vase life evaluations. Acta Hort. 113:171-173.

Reid, M.S., J.L. Paul, M.B. Farnham, A.M. Kofranek, and G.L. Staby. 1980. Pulse treatments with silver thiosulfate complex extend vase life of cut carnations. J Amer. Soc. Hort. Sci. 105:25-27.

Saltveit, M.E. 1989. Effect of alcohols and their interaction with ethylene on the ripening of epidermal pericarp discs of tomato fruit. Plant Physiol. 90:167-174.

Saltveit, M.E. and F. Mencarelli. 1988. Inhibition of ethylene synthesis and action in ripening tomato fruit by ethanol vapors. J. Amer. Soc. Hort. Sci. 113:572-576.

Satler, S.O. and K.V. Thimann. 1980. The influence of aliphatic alcohols on leaf senescence. Plant Physiol. 66:395-399.

Sisler, E.C., M.S. Reid, and S.F. Yang. 1986. Effect of antagonists of ethylene action on binding of ethylene in cut carnations. Plant Growth Reg. 4:213-218.

Veen, H. 1979. Effects of silver on ethylene synthesis and action in cut carnations. Planta 145:467470.

Whitehead, C.S., A.H. Halevy, and M.S. Reid 1984. Control of ethylene synthesis during development and senescence of carnation petals. J. Amer. Soc. Hort. Sci. 109(4):473-475.

Wu, M.J., W. van Doom, S. Mayak, and M.S. Reid. 1989. Senescence of 'Sandra' carnation. Acta Hort. 261:221-225. 